\title{
ESTUDOS SOBRE O DIREITO DE PROPRIEDADE NO MUNDO VIRTUAL: PROTEÇÃO DOS ARQUIVOS DIGITAIS
}

\section{Carlos Alberto Rohrmann ${ }^{1}$}

\section{RESUMO}

A revolução digital tornou mais fácil e mais barato o acesso à propriedade intelectual. Por outro lado, a revolução das telecomunicações digitais que expandiu sobremaneira o mundo digital popularizou as obras digitais por meio da internet. A economia das ideias é bastante disseminada sob a proteção jurídica da propriedade intelectual. Há uma mudança de paradigma do direito de propriedade, por muitos anos associado à existência corpórea do objeto do direito. Este artigo analisa tal mudança, sob a metodologia comparada, com ênfase para a proteção da informação tanto pelo instituto dos segredos de comércio como pelo instituto da proteção possessória.

Palavras-chave: direito digital; mundo digital; propriedade intelectual; segredos comércio; direito comparado

\section{THOUGHTS ABOUT PROPERTY RIGHTS IN THE ONLINE WORLD: LEGAL PROTECTION FOR DIGITAL FILES}

\begin{abstract}
On the one hand, the digital revolution has made it easier and cheaper for consumers to access intellectual property; on the other hand, the telecommunications revolution enhanced enormously the digital world and the access to digital content throughout the Internet. The economy of ideas has become strong under intellectual property protection rules. There is a change in the paradigm of property rights law, that has been, for years associated to the physical existence of its object. This article addresses such a change, under a comparative methodology, emphasizing the protection of information under trade secret law and trespass to chattels theory.
\end{abstract}

Keywords: digital law; digital world; intellectual property rights; trade secrets; comparative law

\section{INTRODUÇÃO}

A internet e o mundo virtual têm causado profundos desafios para o Direito da Propriedade Intelectual. Os motivos são simples: a facilidade de localização da propriedade

\footnotetext{
${ }^{1}$ Doutor em Direito (University of California, Berkeley); Master of Laws (UCLA); Mestre em Direito Comercial (UFMG), Professor do Mestrado, FDMC, Titular da Academia Mineira de Letras Jurídicas, Procurador do Estado/MG. E-mail: crohrmann@mcampos.br
} 
intelectual no mundo virtual, a perfeição e a rapidez das cópias e o baixo custo (que muitas vezes pode se aproximar de quase nada).

Questões relacionadas com a proteção dos arquivos digitais no mundo virtual foram trazidas à baila com a disseminação da internet, fruto da revolução das telecomunicações na segunda metade do Século XX (KRATTENMAKER, 1998) e com a crescente importância da economia das ideias (NEGROPONTE, 2000) e da propriedade intelectual.

O presente artigo pretende estudar as mudanças que o direito de propriedade começa a enfrentar em face da alteração do paradigma dos bens físicos para os bens digitais com ênfase na proteção da informação e do próprio acesso (e preservação) ao arquivo digital.

A metodologia adotada pelo artigo será orientada pela ótica comparativa, o que se justifica pelo conteúdo histórico do direito de propriedade no direito romano e pelas inovações (e adaptações) que o direito anglo-saxônico conferiu ao direito de propriedade tanto para a proteção da informação (segredos de negócio) quanto na proteção do arquivo digital propriamente dito (teoria do trespass to chattels).

O marco teórico que informa nossa metodologia comparada será a teoria do professor catedrático de direito comparado, Laurent Mayali, das universidades da Sorbonne, e de Berkeley, com sua teoria do direito comparado como ciência que permite a atualização dos institutos jurídicos históricos por meio de uma ótica poliédrica (MAYALI, 1995). Assim, vamos visitar institutos jurídicos desde como o direito romano tratava a propriedade (e algumas incursões do direito romano na propriedade intelectual) e institutos do direito inglês da Idade Média e, iluminados pela Teoria de Mayali (MAYALI, 1999), tentarmos atualizar tais institutos para a realidade do mundo digital.

O capitulo dois fará uma breve revisão do direito de propriedade no direito romano, com buscas no Corpus Iuris Civilis aos institutos que podem ser adaptados à era digital; o capítulo três vai pesquisar aspectos econômicos relacionados à economia das ideias na era da informação da propriedade intelectual para fazer a transição para o modelo de proteção dos segredos de negócio trazidos do modelo norte-americano, já analisado no capítulo quatro. Por fim, o capítulo cinco explica como a teoria anglo saxônica do trespass to chattles pode ser usada para proteger os arquivos digitais, por meio de uma comparação na análise de casos norte-americanos e brasileiros. 
$\mathrm{O}$ artigo conclui pela necessidade de adaptação da proteção da propriedade e que a metodologia comparativa vem ao encontro da busca das boas soluções, especialmente em um ambiente transnacional como o mundo virtual.

\section{BREVE REVISÃO HISTÓRICA DO DIREITO DE PROPRIEDADE}

Antes de adentrarmos no estudo do direito de propriedade na era da informação, vamos fazer uma breve pesquisa sobre o direito de propriedade, propriamente dito, com algum enfoque na ótica comparada e no histórico evolutivo do instituto.

O direito de propriedade (CR-88, art. $5^{\circ}$, caput e incisos XXII e XXIII) é garantido no Brasil por força do disposto na Constituição da República de 1988 e do próprio Código Civil de 2002.

O Código Civil de 2002, seguindo a tradição do Código Civil de 1916, não define o direito de propriedade, apenas declina os direitos do proprietário (usar, gozar, dispor e o direito de rever, reivindicar a coisa de quem quer que a possua ou detenha injustamente), “Art. 1.228. O proprietário tem a faculdade de usar, gozar e dispor da coisa, e o direito de reavê-la do poder de quem quer que injustamente a possua ou detenha".

A origem de tais direitos do proprietário, no direito brasileiro, remonta ao direito romano, ou, mais especificamente, ao Corpus Iuris Civilis (A versão do Corpus Iuris Civili sutilizada para a nossa consulta e para a nossa pesquisa é uma tradução do original, em latim, para o inglês: SCOTT, S. P. The civil law including the Twelve Tables, the Institutes of Gaius, the Rules of Ulpian, the Opinions of Paulus, the Enactments of Justinian, and the Constitutions of Leo. Cincinnati: Ed. The Central Trust Company, v. 1).

O Corpus Iuris Civilis foi escrito em Constantinopla, depois da queda do Império Romano do Ocidente, quando Justiniano era o imperador do Império Romano do Oriente Império Bizantino. Trata-se de uma busca do resgate do esplendor do direito romano, determinada por Justiniano.

$\mathrm{O}$ direito de propriedade, no direito romano, era visto como o "direito que liga o homem a uma coisa". Por se tratar de um direito potencialmente absoluto, o direito de propriedade possibilitaria, ao seu titular, retirar da coisa todo o uso e toda a utilidade possíveis (CRETELLA JÚNIOR, 1995, p. 169). Houve, mesmo no direito romano, ao longo dos anos, 
uma evolução no sentido de se tornar o direito de propriedade menos individualista e mais social.

Uma análise da definição romana do direito de propriedade como o direito que dá a ligação do homem à "coisa" decorre como o direito de propriedade estava intimamente associado ao caráter tangível do seu objeto.

Lembre-se de que o termo "coisa" corresponde ao termo res do latim, o qual, no sentido estrito, refere-se apenas àquelas que são dotadas de existência física, embora doutrinadores apontem para dúvidas, dentro do direito romano, quanto à possibilidade de res referir-se também a "outras entidades relevantes para o direito", ou seja "O vocábulo res é tomado ora em sentido restrito, designando apenas o que cai sob os sentidos - tudo que tem existência real, no mundo concreto, ora tal sentido é alargado pelas investigações e exigências dos juristas a ponto de abranger a res incorporales." (CRETELLA JÚNIOR, 1995, p. 151). Todavia, como se depreende da lição do professor Cretella Júnior, transcrita a seguir, não se poderia dizer que o termo jurídico res teria chegado a abranger, no direito romano, as obras do espírito humano "Nunca, porém, a mentalidade prática e concreta do romano chega a rotular como res certas entidades imateriais como serviços, prestações pessoais, obras do espírito humano, irredutíveis a algo material” (CRETELLA JÚNIOR, 1995, p. 165).

A evolução do direito de propriedade aponta uma primeira fase como sendo um direito voltado, principalmente, para o bem tangível, especialmente com vista à proteção dos bens imóveis.

O direito de propriedade sobre os bens móveis, inicialmente uma consequência lógica do direito sobre os imóveis, tornou-se mais elaborado ao longo da Idade Média e da Idade Moderna.

Por fim, foi somente há menos de trezentos anos que surgiu a proteção específica do direito da propriedade intelectual, com a edição das primeiras leis de copyright na GrãBretanha, como se verá adiante.

Nota-se que no texto do Corpus Iuris Civilis também há referências ao direito sobre a "propriedade incorpórea". Todavia, tal direito referia-se mais a "direitos", como o direito de herança e os direitos de usufruto (Corpus Iuris Civilis, ed. cit., Título II, itens 1 e 2, v. 2.) e de servidão, no item 3 do título III, do que a direitos sobre propriedades intelectuais, como os direitos autorais e as patentes. 
Curiosamente, apesar de a edição de lei de copyright somente ter surgido no final da Idade Média, um estudo mais aprofundado do Corpus Iuris Civilis aponta para algumas manifestações da presença do embrião do Direito da Propriedade Intelectual no direito romano.

Tal manifestação está presente no trecho do Corpus Iuris Civilis que trata da chamada acessão física. A princípio, é considerado bem imóvel tudo aquilo que o homem incorporar definitivamente ao solo, uma vez que o Corpus Iuris Civilis determina que, por exemplo, a planta originada da semente lançada à terra pertence ao "dono da terra", ainda que a semente seja de terceiro. Ou seja, tudo aquilo que o homem incorporar permanentemente ao solo pertence ao dono do solo como um bem imóvel (ainda que proveniente de terceiro, com direito a indenização em certos casos). Assim também dispõe o art. 79 do Código Civil Brasileiro. Ressalta-se que o revogado Código Civil de 1916 era mais específico ao tratar, em seu art. 43, da "semente lançada ao solo" como um bem imóvel (trata-se de uma redação, digamos, mais próxima daquela do direito romano, adotada pelo texto do Corpus Iuris Civilis).

O interessante é que o Corpus Iuris Civilis vai além do exemplo da semente e preceitua que até mesmo os escritos de terceiros devem pertencer ao dono do papel, e não àquele que redigiu o texto, Corpus Iuris Civilis, ed. cit., Título I, item número 33, v. 2, senão vejamos:

(33) O escrito, também, ainda que se pense em escrito de ouro, pertence ao papiro, assim como as edificações e as plantas pertencem ao solo; e, consequentemente, se Titius tiver escrito um poema, uma estória ou um discurso, no seu papiro, você, e não Titius, há de ser considerado como o dono do escrito. (tradução nossa)

Apesar desta regra geral da propriedade, seja por acessão física, no caso da semente lançada à terra, ou, ainda, no caso das edificações, seja por acessão intelectual, no caso do escrito em papel de outrem, há algumas exceções no Corpus Iuris Civilis. Cuida-se de algumas dúvidas que são levantadas em hipóteses de pinturas, o que pode corresponder ao início do reconhecimento do direito de propriedade intelectual ou da proteção jurídica das chamadas "obras do espírito", conforme se depreende do texto que segue imediatamente ao número (33), transcrito anteriormente: 
(34) Quando alguém pinta na tela de outrem, algumas pessoas pensam que a tela deveria pertencer à pintura, e outros são de opinião que a pintura, seja de que tipo for, é parte da tela. Parece-Nos (sic) preferível que a tela deva pertencer à pintura, uma vez que seria ridículo que uma pintura de Apelles ou de Parrhasius pudesse ser considerada a adição a uma tela. Assim, se uma pessoa estiver na posse de uma tela e o artista que a pintou resolve demandá-la, se este último não estiver disposto a pagar o preço da tela, ele pode ser impedido com base na fraude; mas se ele, que a pintou, estiver de posse dela, decorrerá que uma ação pode ser ajuizada contra ele pelo dono da tela, de forma que, se não pagar o preço da pintura, em todos os casos, ele também poderá ser impedido por uma exceção com fundamento na fraude; se ele, quem a pintou, obteve a posse da tela em boa-fé, é evidente que, se o artista ou qualquer terceiro adquirir a tela sub-repticiamente, o seu dono terá um direito de ação por furto. (tradução nossa)

Assim, pode-se concluir que até mesmo Justiniano já admitia que seria um erro considerar sempre que ao dono da tela pertenceria a pintura (é interessante que também o revogado Código Civil Brasileiro de 1916, em seu art. 62, excepcionava a pintura em relação à tela, como benfeitorias acessórias). Esta regra demonstra a importância da propriedade intelectual como algo que se desprende de seu suporte físico. Em outras palavras, caso alguém seja dono do suporte físico onde está alguma propriedade intelectual, isto não lhe confere, por si só, algum direito de propriedade sobre a obra intelectual, ou a "obra do espírito".

O direito da Common Law, por seu turno, como um sistema bem menos elaborado e bem menos abstrato do que o direito romano, cuidou do direito de propriedade de duas formas (MAITLAND e POLLOCK, 1968, p. 87), a "propriedade real" que se referia à terra e a “propriedade pessoal” que tratava dos bens móveis (BAKER, 1990, p. 34).

A "propriedade real" da Common Law, dada a sua grande importância durante a Idade Média, por ser o local onde as pessoas moravam e dela retiravam o seu sustento, seja pela agricultura, seja pela criação de animais, era regulamentada pelo regime feudal (feudal tenure). O direito do regime feudal de propriedade (feudal tenure), que era bastante complexo, dados os direitos e as obrigações dos senhores feudais e dos servos que habitavam a terra (BAKER, 1990, p. 255).

O direito que regulamentava a "propriedade pessoal" da Common Law, por seu turno, foi bastante singelo, devido à falta de valor econômico dos bens móveis durante a Idade Média (o que era explicado pelo feudalismo e a excessiva valorização da terra, além do fato de a atividade comercial ter sido relativamente pequena durante o período feudal na GrãBretanha). É claro que mesmo durante o feudalismo já se desenvolvia o direito de propriedade 
sobre bens móveis na Grã-Bretanha, mas foi com o advento da Revolução Industrial que o direito de propriedade pessoal, ou o direito de propriedade sobre os bens móveis consolidouse.

A Common Law adotou o termo chattels (BAKER, 1990, p. 248) para o bem móvel (um termo que tem origem na língua francesa) e, segundo o regime da Common Law, o direito de propriedade sobre um chattel começava pela sua criação ou pela feitura de uma coisa nova. Trata-se da aplicação da teoria romana da specificatio, segundo a qual a coisa pertence ao seu fabricante, àquele que, com as suas mãos, fez a coisa.

Assim como o direito da propriedade móvel decorreu da evolução do feudalismo e, principalmente, da grande mudança trazida pelo comércio e pela Revolução Industrial, o Direito de Propriedade Intelectual também surgiu como decorrência da técnica, ou, mais especificamente, do surgimento da imprensa.

O primeiro direito de "copyright" foi conferido por um decreto real em 1556, na GrãBretanha, pouco após o advento da imprensa (MERGES, 1997, p. 321). Há discussões na doutrina no que se refere à existência de outros decretos semelhantes e anteriores a esse, o que não invalida a importância do decreto de 1556 (MERGES, 1997, p. 122).

A primeira lei inglesa que regulamentou o copyright foi o Statute of Anne, passada pelo parlamento britânico em 1710. Esta lei conferia aos autores o direito exclusivo sobre as suas obras, por um prazo de quatorze anos, renováveis por outro período de mais quatorze anos.

O direito continental foi conhecer a proteção legal dos direitos dos autores também no Século XVIII. Pode-se exemplificar com a França, que teve um decreto editado pelo governo revolucionário em 1791, decreto este que dispunha sobre uma série de direitos morais dos autores.

Outros exemplos de leis protetivas da propriedade intelectual que demonstram a evolução histórica do instituto da propriedade podem ser aquelas que se referem aos direitos sobre as marcas registradas e sobre as patentes de invenções.

Os dois exemplos das marcas e das patentes têm seu surgimento intimamente ligado ao desenvolvimento do comércio, motivo pelo qual o Direito Canônico e o direito da Common Law não foram os precursores da proteção.

Quanto às patentes, foi em Veneza, uma cidade-estado que se dedicou ao comércio, que surgiu a primeira lei, com origem no senado veneziano, em 1474. A Lei de Veneza 
conferia ao inventor um privilégio ou monopólio sobre a invenção pelo prazo de dez anos (MERGES, 1997, p. 122). Também em Florença, então cidade-estado dedicada ao comércio, houve as primeiras manifestações de proteção de direitos dos inventores, semelhantes ao direito das patentes (MERGES, 1997, p. 123).

O direito da Common Law britânica só foi conhecer o instituto das patentes em meados do Século XVI (MERGES, 1997, p. 524) e, posteriormente, o direito foi levado para os Estados Unidos.

Quanto às marcas, há casos ingleses do início do Século XIX que já reconheciam a proteção jurídica das marcas contra o uso por terceiros. A proteção deslocou-se da Common Law para a proteção legal nos Estados Unidos, com a primeira lei federal sobre o tema em 1870 (MERGES, 1997, p. 524).

A evolução que vimos muito brevemente neste capítulo demonstra que a proteção jurídica tende a ser tão mais elaborada para a propriedade conforme a época e conforme o tipo de propriedade que tem a maior importância prática e econômica na vida das pessoas.

Uma tendência também notada em relação ao direito de propriedade é a observância da função social como um fator limitador do antigo direito absoluto que a propriedade oferecia ao dono em relação ao seu bem.

A chamada função social da propriedade está contida em preceito da Constituição do Brasil e foi também detalhada no Código Civil Brasileiro de 2002 (art. 5º, inciso XXIII). É incontestável que a função social da propriedade aplica-se também à propriedade intelectual e industrial, uma vez que a Constituição da República não a excepcionou e, como se depreende, por exemplo, das quebras de patentes de medicamentos em certos casos específicos.

Atualmente, vemos um crescimento da importância da propriedade intelectual, seja por meio da indústria do entretenimento que demanda proteção para os programas de computador, para as músicas, para os filmes e para os jogos em geral; seja por meio da indústria que necessita das proteções patentárias para suas invenções e para os seus modelos de utilidade com aplicações industriais.

Observa-se, ainda, o aumento da importância da informação na economia, informação está presente não só em obras protegidas pela propriedade intelectual, como em bancos de dados (os quais, a princípio, não receberiam proteção). Destarte, passamos agora a uma explicação das formas de adaptação que o direito de propriedade vive em relação à 
proteção dos bens imateriais, com foco nos desafios trazidos pela virtualização da propriedade intelectual.

\section{ALGUNS ASPECTOS ECONÔMICOS DA PROTEÇÃO JURÍDICA DA INFORMAÇÃO}

A importância da informação como uma verdadeira "mercadoria" do mundo virtual é evidenciada nos serviços dos web sites de busca na rede. Nota-se que a informação, independentemente do suporte físico em que se encontra, é sempre um bem não dotado de existência física, uma vez que a informação se refere a uma ideia, ou ao acréscimo de um certo conhecimento já existente.

A proteção da informação será ou pelo Direito da Propriedade Intelectual ou por alguma forma análoga, como as normas contra a concorrência desleal.

Há algumas características econômicas dos bens imateriais que são importantes de serem rapidamente analisadas, em função das consequências para o direito. Tais conceitos econômicos são aplicáveis aos bens imateriais economicamente apreciáveis. Em especial, podemos exemplificar os programas de computador e as informações utilizadas nos mercados da internet. Tomaremos os programas de computador como exemplo a ser analisado, por se tratar de área onde a informação é extremamente valiosa e, ao mesmo tempo, juridicamente protegida no Brasil sob o regime dos direitos de autor (embora nos Estados Unidos admitamse patentes de programas de computador - software patents).

Dois conceitos econômicos são, pois, aplicáveis aos programas de computador: "bens públicos" (e aqui, ressalta-se, não se faz qualquer referência ao conceito jurídico de bens públicos, mas a um conceito econômico) e os chamados "efeitos de rede".

Os "bens públicos da economia", por seu turno, apresentam duas características marcantes: a "não exclusão" e o chamado "uso não rival".

A "não exclusão" refere-se à dificuldade de se impedir que aqueles que não pagaram pelo bem consumam o bem (ou extraiam dele as suas utilidades da mesma maneira como aqueles que pagaram pelo bem). A grande pirataria de programas de computador que é vista ao redor do mundo demonstra bem esta característica. Caso uma pessoa adquira o programa de computador legalmente, pagando pela licença de uso, e resolva fazer muitas cópias dele para seus amigos, estes o usarão e dele poderão extrair todas as mesmas utilidades como 
aquele que pagou pelo programa. É muito difícil de se impedir este uso dos que não pagam pelo programa de computador. O advento da internet tornou esta característica ainda mais evidente. Basta que a pessoa que adquire legalmente o programa de computador o disponibilize em uma página na rede para qualquer interessado, por meio da internet, fazer cópias idênticas do programa. Esta prática, despida de qualquer interesse comercial por parte daquele que mantém a página na rede com a versão do programa a ser copiado, tornou-se tão comum ao longo da década de noventa que chegou a motivar a edição de lei que criminaliza tal "furto eletrônico" na terminologia do direito norte-americano. Cuida-se do The No Electronic Theft Act, de 1997, que criminalizou a feitura de cópias, com fins comerciais, ou até sem fins lucrativos, desde que as cópias de obras protegidas por direitos autorais (inclusive fonogramas) excedam o valor de mil dólares norte-americanos, no prazo de 180 dias. Nota-se que o exemplo do programa de computador pode ser aplicado a outras obras protegidas por direitos autorais, como as músicas em arquivos de computador:

CRIMINAL INFRINGEMENT- Any person who infringes a copyright willfully either--

(1) for purposes of commercial advantage or private financial gain, or

(2) by the reproduction or distribution, including by electronic means, during any 180-day period, of 1 or more copies or phonorecords of 1 or more copyrighted works, which have a total retail value of more than $\$ 1,000$ shall be punished as provided under section 2319 of title 18, United States Code. For purposes of this subsection, evidence of reproduction or distribution of a copyrighted work, by itself, shall not be sufficient to establish willful infringement.

A outra característica econômica dos "bens públicos" é aquela chamada de "uso não rival". Ela também é aplicável aos programas de computador e às músicas digitais. Trata-se da característica segundo a qual novos consumidores do bem intangível, como os programas de computador, não diminuem a quantidade de bens (programas de computador) disponíveis para os demais consumidores. A internet demonstra bem esta característica, na medida em que caso uma pessoa resolva fazer a cópia daquele programa de computador disponibilizado em um determinado web site, gratuitamente, isto não impede que todas as outras que queiram fazer cópias o façam (LEMLEY, 2000).

Muitos críticos da proteção que a propriedade intelectual empresta aos programas de computador valem-se destas duas características dos "bens públicos da economia" para 
argumentar que a proteção seria "artificiall". Este argumento decorre do fato de o direito de propriedade, em termos gerais, servir para ligar o homem à coisa que é escassa por definição e, por consequência, para garantir, juridicamente, esta escassez. Assim, caso se trate de um lote de terra, ou de um quilo de sementes, em ambos os casos, é fácil excluir aqueles que não pagaram pelos produtos ou pelos benefícios e utilidades que se podem extrair daquelas coisas. Ao mesmo tempo, mais consumidores de lotes ou de sementes vão diminuir a quantidade de lotes e de sementes disponíveis para negócios, e, desta feita, conforme a lei da oferta e da procura, haverá consequências nos preços dos bens. Cumpre ao direito garantir que aquele que tem um lote de terra ou um quilo de sementes possa ter juridicamente assegurado o seu direito de excluir os terceiros de qualquer benefício decorrente do direito de propriedade. Tal hipótese, segundo os críticos da propriedade intelectual, não acontece com os bens intangíveis porque não haveria custo com a feitura de novas cópias (como no exemplo do programa de computador ou dos arquivos de música digital e de sons disponibilizados pela internet, de graça, para cópias piratas).

O outro conceito econômico aplicado aos programas de computador e aos demais bens intangíveis protegidos pelo Direito da Propriedade Intelectual é o "efeito de rede" (além de outras situações econômicas, como serviços ou até mesmo o conhecimento de idiomas, como se verá a seguir).

Este efeito de rede diz respeito à característica econômica de certos produtos que tendem a ter a satisfação do consumidor aumentada na medida em que também aumenta o número de consumidores daquele mesmo produto. Trata-se de uma consequência da padronização que é tão desejada pelos consumidores de certos produtos, como no caso dos programas de computador, e de produtos de tecnologia, por exemplo.

O "efeito de rede" pode ser exemplificado com o caso do serviço de telefonia fixa comutada. Quanto maior o número de pessoas que têm aparelhos telefônicos (e, por conseguinte, acesso ao serviço telefônico) tanto mais interessante será para um consumidor adquirir o serviço, porque conseguirá comunicar-se com um número maior de pessoas. Um outro exemplo interessante é o padrão de disposição das teclas do teclado das máquinas de escrever, que foi adaptado para os teclados de computador. O chamado padrão "QWERTY" foi transportado para os computadores em atendimento ao efeito de rede (LEMLEY, 2000, p. 34). Como praticamente todos os datilógrafos já conheciam e usavam o padrão "QWERTY", 
nada melhor do que mantê-lo nos teclados de computador, ainda que o padrão não seja o melhor.

O conhecimento de idiomas também apresenta o efeito de redes. É o caso da língua inglesa que, por ser uma espécie de "idioma internacional”, acaba por ter a preferência como "segunda língua".

A tendência à padronização decorrente do efeito de rede no caso dos programas de computador tem como consequências o retardamento da evolução dos produtos e uma perigosa tendência à formação de monopólios, quase sempre indesejados pela concorrência e combatidos no âmbito do Direito Econômico.

Um problema associado à tendência de monopolização que decorre da padronização é a própria forma de proteção jurídica da propriedade intelectual, seja por meio do direito autoral (ou do copyright), seja mediante a concessão de patentes. Em ambos os casos, o direito está a conferir um monopólio temporário legal, o que representa mais um fator que contribui para a formação de monopólios empresariais.

A proteção jurídica de bens imateriais, como a informação, é, pois, algo complexo do ponto de vista da técnica jurídica. Essa complexidade decorre da necessidade de se fazer adaptação no instituto da propriedade para torná-lo eficiente no tocante ao atendimento das garantias de uso exclusivo e de uso rival para os bens imateriais (o que, como visto, contraria a própria natureza econômica de tais bens).

A tecnologia permite que a propriedade intelectual venha a se desprender, cada vez mais, do seu suporte físico. Enquanto, até pouco tempo atrás, um livro somente podia ser disponibilizado em papel, um suporte tangível, atualmente, já se pode ter o livro digital, no qual a propriedade intelectual figura completamente desassociada de uma base física tangível.

Uma forma interessante de proteção que foi evoluindo ao longo dos anos para atender às necessidades de proteção à informação intangível, porém, economicamente apreciável, é o segredo do comércio, como se verá a seguir.

\section{SEGREDOS DO COMÉRCIO}

É inegável a existência de certas informações empresariais sigilosas que têm considerável valor econômico para a indústria e para o comércio. Imagine-se, por exemplo, a 
fórmula de determinada bebida de grande consumo mundial ou o método de alguma atividade de logística.

Quando se pensa na forma jurídica de se obter proteção para informações sigilosas e valiosas para as empresas, um primeiro instituto a ser utilizado seria o da patente. Com a patente, o titular do direito teria um direito de propriedade com todos os benefícios de tão importante direito.

Sabe-se que a patente é um monopólio temporário, conferido pelo Estado ao titular, em troca das informações de como fazer o objeto da patente. As informações são posteriormente publicizadas para que, após a queda das patentes, já em domínio público, outras pessoas possam explorar o que foi, no passado, objeto da proteção patentária.

A solução de se pedir uma patente pode não ser muito interessante em certos casos de segredos comerciais em função do prazo de proteção de apenas vinte anos contados da concessão da proteção.

Ademais, ocorrem certas situações e certos casos de segredos do comércio que não são, em tese, passíveis de receberem proteção patentária por não se enquadrarem nas hipóteses legais próprias.

Um instituto jurídico que surgiu e teve considerável desenvolvimento no regime da Common Law é o que protege, como direito de propriedade, os chamados "segredos do comércio", também conhecido como trade secrets no direito norte-americano.

As raízes do direito dos segredos estão fincadas na Revolução Industrial Britânica. A origem do instituto jurídico do trade secretremonta às decisões das cortes britânicas de proteção aos segredos (British SecrecyLaws) que surgiram ao longo da Revolução Industrial, como uma forma de proteção, à época, ainda dentro do instituto do dano civl (torts). Os primeiros casos na Grã-Bretanha foram decididos em 1817, e, nos Estados Unidos, em 1837 (MERGES, 1997, p. 30).

Segundo o regime do trade secret norte-americano, merece proteção como direito de propriedade o segredo que tenha valor econômico e sobre o qual sejam gastos esforços para que o segredo seja mantido afastado do conhecimento de terceiros, dos concorrentes e do grande público, o que ficou decidido em um caso (Kewanee Oil Co. v. Bicron Corp., 416 U. S. 470, 1974) da Suprema Corte dos Estados Unidos, em 1974 (trata-se do surgimento de uma decisão judicial da suprema corte norte-americana que, de certa forma, curiosamente, "cria" um direito de propriedade). 
A proteção do direito norte-americano leva em conta alguns fatores para se determinar se uma informação pode ou não merecer a proteção jurídica do trade secret. Dentre tais fatores citam-se alguns quesitos a serem respondidos, relativos a até que ponto a informação da empresa: a) - é conhecida por terceiros fora da atividade empresarial; b) - é de conhecimento dos próprios empregados que trabalham na empresa; c) - tem valor para a própria empresa e para seus concorrentes; d) - poderia ser facilmente adquirida ou alcançada mediante pesquisa por terceiros; e) - decorreu de gastos empresariais em sua pesquisa e em seu desenvolvimento; e, f) - é efetivamente mantida em sigilo pelos esforços (inclusive econômicos) dentro da atividade empresarial.

O objeto da proteção dos trade secretsé a informação sigilosa, o segredo (que não precisa ser absoluto, pode ter um pequeno descortinamento para alguns empregados ou para empresas fornecedoras, por exemplo) economicamente apreciável. Em termos exemplificativos, qualquer fórmula, padrão, compilação, programa, dispositivo, método, técnica ou processo sigilosos e valiosos poderiam merecer, em tese, proteção jurídica sob o trade secret norte-americano.

Ainda sobre o objeto do trade secret, a jurisprudência norte-americana vem aceitando a definição contratual do que seria um trade secret. É uma curiosa situação de quase criação de direito de propriedade por via contratual (caso do "Listerine", Warner-Lambert Pharmaceutical Co. v. John J. Reynolds, Inc., United States District Court for Southern District of New York,178 F. Supp. 655, S.D.N.Y. 1959).

A legislação brasileira não confere, ainda, direito de propriedade ao titular do segredo do comércio, mesmo porque o direito de propriedade, no Brasil, decorre de lei e existe em números fechados.

A Lei n. 9.279, de 14 de maio de 1996, que regula os direitos e as obrigações relativos à propriedade industrial, em seu art. 195, trata dos chamados "crimes de concorrência desleal". Alguns dos referidos crimes, especialmente os tipificados nos incisos XI, XII e XIV, cuidam de uma proteção criminal similar àquela dispensada aos trade secrets, conforme se depreende da leitura de tais dispositivos de lei, transcritos a seguir:

Art. 195. Comete crime de concorrência desleal quem:

$[\ldots]$

XI - divulga, explora ou utiliza-se, sem autorização, de conhecimentos, informações ou dados confidenciais, utilizáveis na indústria, comércio ou prestação de serviços, excluídos aqueles que 
sejam de conhecimento público ou que sejam evidentes para um técnico no assunto, a que teve acesso mediante relação contratual ou empregatícia, mesmo após o término do contrato;

XII - divulga, explora ou utiliza-se, sem autorização, de conhecimentos ou informações a que se refere o inciso anterior, obtidos por meios ilícitos ou a que teve acesso mediante fraude; ou

$[\ldots]$

XIV - divulga, explora ou utiliza-se, sem autorização, de resultados de testes ou outros dados não divulgados, cuja elaboração envolva esforço considerável e que tenham sido apresentados a entidades governamentais como condição para aprovar a comercialização de produtos.

$[\ldots]$

Pena - detenção, de 3 (três) meses a 1 (um) ano, ou multa.

A doutrina brasileira considera estes os principais textos de lei que têm referência à proteção dos segredos do comércio no Brasil (FEKETE, 2001; DINIZ, 2003). Importante destacar quão pequena é a pena fixada pela legislação brasileira para um crime tão grave, que pode gerar consequências econômicas tão nefastas para as empresas atuantes neste país, como o caso dos crimes de concorrência desleal.

Algumas críticas à legislação brasileira residem no fato de a mesma não chegar a conferir o direito de propriedade (como uma modalidade da propriedade industrial) ao segredo do comércio. Trata-se de uma tendência que vem crescendo, o que assegura maior tranquilidade ao empresário.

A proteção por direito de propriedade talvez seja favorável às pequenas empresas que, ao contrário das grandes companhias, não dispõem de grandes somas para investir na segurança e na manutenção do sigilo.

Por outro lado, assegurar um direito de propriedade sobre uma informação também pode ser perigoso para o desenvolvimento da ciência e da tecnologia, máxime quando se pensa na possibilidade de, assim como o direito norte-americano permite, reconhecer o estabelecimento, por contrato, de um determinado sigilo de comércio que seria protegido sob o pálio do direito de propriedade.

Uma vez que vimos neste tópico a possibilidade de se estender o conceito de propriedade para alcançar a informação, por meio do trade secret, vamos agora para uma breve explicação sobre a possibilidade de se aplicar a proteção possessória aos arquivos digitais.

\section{POSSE SOBRE ARQUIVOS DIGITAIS}


Antes de se adentrar no estudo da possibilidade da aplicação da proteção possessória para os arquivos digitais de computador, e, desta forma, proteger a informação que eles contêm, devem ser analisadas as inovações do Direito Civil Brasileiro em relação aos bens móveis. Assim dispõe o Código Civil Brasileiro sobre os bens móveis:

Art. 82. São móveis os bens suscetíveis de movimento próprio, ou de remoção por força alheia, sem alteração da substância ou da destinação econômico-social.

Art. 83. Consideram-se móveis para os efeitos legais:

I - as energias que tenham valor econômico.

$[\ldots]$

Uma importante inovação do Código Civil foi estender o conceito de bem móvel às “energias que tenham valor econômico". É inegável que os arquivos digitais de computador são "energia armazenada", seja em meio magnético (discos flexíveis de computador do tipo "disquetes" ou discos rígidos de computador do tipo "HDs"), seja em meio ótico (discos do tipo “CDs”).

Há, também, induvidosamente, o direito de propriedade sobre o meio físico que armazena os arquivos digitais. O dono do computador é o dono, o proprietário dos discos onde estão gravados os dados sob a forma de arquivos digitais.

Para a análise que será desenvolvida neste capítulo, vamos desprendermo-nos da proteção de propriedade intelectual que incide sobre o conteúdo dos arquivos digitais. Tais arquivos podem conter programas de computador ou arquivos de música digital, por exemplo. Nota-se que a criação intelectual representada pelos arquivos digitais, como no caso dos exemplos acima, pode ser protegida, indiscutivelmente, pelo Direito de Autor (ou pelo regime do copyright do direito anglo-saxão), uma forma de proteção à propriedade intelectual.

Há, no direito brasileiro, consenso no sentido de que o direito possessório não alcança a proteção de direitos pessoais nem os direitos autorais (conforme a súmula 228 do STJ - "É inadmissível o interdito proibitório para proteção do direito autoral"). A primeira interpretação poderia ser na direção de que não cabem os interditos possessórios para a proteção dos arquivos digitais.

Embora o STJ não admita a proteção possessória de direitos autorais, há algumas situações interessantes no caso das linhas telefônicas. Existe, no direito brasileiro, a possibilidade de se usucapir o direito de uso de linha telefônica. Deste direito, decorre, 
logicamente, que existe posse do direito de uso da linha telefônica, o que abre margem para uma interpretação no sentido de que seria possível a proteção possessória também para os arquivos de computador.

Nota-se que a justiça brasileira já pacificou o tema da possibilidade de se conceder proteção possessória no caso das linhas telefônicas, uma vez que o Superior Tribunal de Justiça sumulou que o direito de uso de linha telefônica é susceptível de aquisição por usucapião (súmula 193 do STJ - "O direito de uso de linha telefônica pode ser adquirido por usucapião").

É bem verdade que a súmula do STJ faz referência ao "direito de uso" de linha telefônica como aquele que seria susceptível de posse e, consequentemente, usucapível. Por outro lado, um ponto da maior importância que se retira dos acórdãos do STJ que trataram da matéria é o que se refere à distinção entre direito pessoal (este não sujeito a usucapião) e o direito real (este sim, sujeito a usucapião).

A jurisprudência brasileira firmou, pois, entendimento pela posição doutrinária de que o direito de uso de linha telefônica é um direito real. Não restam dúvidas de que tal direito sobre as linhas telefônicas não é dotado de existência física, da mesma forma que os arquivos digitais não o são.

A doutrina civilista tradicional assim conceitua o direito real (BARROS MONTEIRO, 1976, p.11):

[...] o direito real pode, destarte, ser conceituado como relação jurídica em virtude da qual o titular pode retirar da coisa, de modo exclusivo e contra todos, as utilidades que ela é capaz de produzir. O direito pessoal, por seu turno, conceitua-se como relação jurídica mercê da qual ao sujeito ativo assiste o poder de exigir do sujeito passivo determinada prestação, positiva ou negativa.

Da lição do professor Washington de Barros extrai-se que o direito sobre os arquivos digitais poderia ser considerado como um direito real, haja vista a possibilidade de o titular retirar as utilidades, por exemplo, de um determinado web site, o que, sob a garantia jurídica, há de lhe ser deferida de forma exclusiva.

Outros aspectos que também são encontrados nos acórdãos (STJ, RESP no. 34.774-2, São Paulo) que tratam da proteção possessória para linhas telefônicas dizem respeito ao seu valor elevado (obviamente antes da privatização das chamadas teles, o que, em muito, reduziu 
o preço de instalação de uma linha telefônica) bem como ao da negociabilidade das linhas telefônicas. Ora, ambos os itens são aplicáveis nos casos de web sites.

É indiscutível o valor econômico de um site tão visitado como o das páginas comerciais de empresas que operam no mundo virtual e, não restam dúvidas, tal site pode ser negociado (o que acontece, e muito, por exemplo, nos casos das páginas muito populares das redes sociais).

Assim, poder-se-ia aplicar a proteção possessória para os arquivos digitais de um web site em certos casos de turbações à posse no mundo online.

Exemplos práticos de situações que configurariam a turbação possessória de um web site podem ser algumas situações análogas às seguintes: Um determinado operador de computador dirige suas atividades para um web site para retirar-lhe dados (fazer cópias excessivas de tais dados); como não há, a princípio, proteção de direitos autorais sobre os dados copiados, o titular do web site poderia conseguir uma liminar possessória para impedir que o terceiro viesse a acessar o web site (a turbação possessória residiria no fato de que os computadores que hospedam o web site estivessem sendo sobrecarregados pelo excesso de acessos oriundos de terceiro com uma consequente perda de desempenho, perda esta que poderia ser prejudicial caso se tratasse de um web site de empresa de comércio eletrônico, que teria os possíveis clientes insatisfeitos). Neste exemplo, poder-se-ia falar em uma proteção, ainda que por via oblíqua, às informações contidas no web site.

Outro caso é a aplicação da proteção possessória para impedir o envio de spam. Tome-se o caso de um provedor de acesso à internet, cujos computadores armazenam os $e$ mails ainda não lidos dos seus clientes. Seus computadores se encontram sobrecarregados por envio excessivo de mensagens oriundas de um mesmo computador. Trata-se de um prejuízo para o provedor, uma vez que os acessos aos seus computadores estariam sempre sobrecarregados pelo número excessivo de e-mails que são recebidos continuadamente. Também aqui o provedor poderia conseguir uma ordem de proteção possessória para que aquele que envia os e-mails excessivos fosse proibido de turbar-lhe a posse sobre seus computadores, e, por consequência, sobre os arquivos digitais (Há caso decidido nos Estados Unidos com fatos muito próximos aos do exemplo acima: CompuServe v. CyberPromotions, 962 F.Supp. 1015, S.D.Oh. 1997).

\section{CONCLUSÃO}


$\mathrm{O}$ artigo demonstrou que o direito da propriedade vem sendo adaptado desde o direito romano para enfrentar as mudanças que a sociedade passou e que a economia sofreu ao longo de mais de vinte séculos. Em um primeiro momento, ainda na década de noventa do século passado, uma certa estupefação pode ter levado alguns acadêmicos a enfrentarem a questão da possível ineficiência do direito para regulamentar o mundo digital (BIEGEL, 2001); todavia, apresentamos nessa obra, propostas de soluções para a propriedade no mundo digital (ROHRMANN, 2007).

As inovações trazidas pela informática e suas consequências para o direito (ROVER, 2000, p. 43) foram das mais relevantes para a sociedade nos últimos cinquenta anos (ROVER, 2004, p. 85) com impactos decisivos para as mudanças dos direitos reais. O mundo online, ou mundo virtual é a cada dia mais presente na propriedade intelectual (ROHRMANN, 2015, p. 37).

Em face do aspecto transnacional do mundo online (LEVY, 1996), sem embargo dos reflexos no direito internacional (CARTER e TRIMBLE, 1995, p. 348); entendemos que o estudo do direito comparado pode trazer importantes subsídios para novas propostas de adpatação dos institutos jurídicos ao mundo digital.

A nossa escolha pela teoria do direito comparado poliédrico do Professor Mayali como marco teórico, sem embargo da nossa adesão à também teoria da dogmática jurídica para a regulamentação do direito digital (ROHRMANN, 2004), mostrou-se efetiva para orientar as adaptações necessárias aqui apresentadas e propostas para o direito de propriedade na medida que foram verificadas por casos decididos não só pela justiça norte-americana como também pelo próprio precedente analisado do Superior Tribunal de Justiça que, embora sem nenhuma relação direta, enfrentaram a questão da posse de bens digitais trazidos pela telemática de forma curiosamente bastante análoga.

\section{REFERÊNCIAS}

BAKER, J. H. An introduction to English legal history. $3^{\mathrm{a}}$ ed. Londres: Butterworths Reed Elsevier, 1990.

BARROS MONTEIRO, Washington. Direito das Coisas. 16ª ed. São Paulo: Saraiva, 1976. 
BIEGEL, Stuart. Beyond Our Control? Confronting the Limits of Our Legal System in the Age of Cyberspace. Cambridge: MIT Press, 2001.

CARTER, Barry E. e TRIMBLE, Phillip R. International law. Second edition. Boston: Little, Brown and Company, 1995.

DINIZ, David Monteiro. Propriedade industrial e segredo de comércio. Belo Horizonte: Ed. Del Rey, 2003.

FEKETE, Elisabeth Kasznar. O regime jurídico do segredo de indústria e comércio no direito brasileiro. Rio de Janeiro: Forense, 2003.

KRATTENMAKER, Thomas G. Telecommunications Law and Policy. 2a ed. Durham: Carolina Academic Press, 1998.

LEMLEY, Mark A. et al. Software and internet law. Boston: Aspen Law \& Business, 2000.

LEVY, Pierre. O que é o virtual? São Paulo: Ed. 34, 1996.

MAITLAND, William e POLLOCK, Frederick. The history of English Law before the Time of Edward, I vol. 2, 2a. ed., Cambridge, Ed. Univ. Press, 1968.

MAYALI, Laurent. Social practices, legal narrative, and the development of the legal tradition. Chicago-Kent Law Review, 1999.

MAYALI, Laurent et al. Symposium on Ancient Law, Economics \& Society. Chicago: Chicago-Kent College of Law, 1995.

MERGES et al. Intellectual property in the new technological age. New York: Aspen Law and Business, 1997.

NEGROPONTE, Nicholas. A Vida digital. São Paulo: Companhia das Letras, 2000.

ROHRMANN, C. A. Introduction to the online world. 1. ed. Los Angeles: Master Building Publishers, 2015. 
ROHRMANN, C. A. The Dogmatic Function of Law as a Legal Regulation Model for Cyberspace. The UCLA Online Institute for Cyberspace Law and Policy, Los Angeles, 2004.

ROHRMANN, C.A. The role of the dogmatic function of law in cyberspace. International Journal of Liability and Scientific Enquiry, v. 1, p. 85, 2007.

ROSSINI, Augusto. Informática, Telemática e Direito Penal. São Paulo: Memória Jurídica, 2004.

ROVER, Aires José et al. Direito sociedade e informática. Florianópolis: Boiteux, 2000.

ROVER, Aires. Direito e informática. Barueri: Manole, 2004. 